\title{
A Meta-Critical Analysis of Ceramics Criticism For Art Education: Toward an Interpretive Methodology
}

\author{
Booker Stephen Carpenter, II
}

Ceramic art defies easy categorization-it steps over the boundaries between fine art, design, industry, and craft-and for that reason, it seems to elude understanding.

-Michael McTwigan ${ }^{\top}$

Our culture is and will increasingly become diverse, comprised of plural, discontinuous, disputed realities. The arts can be primary vehicles with which to navigate differences and articulate ourselves to each other. The alternative to such openness is a sterile, narrow and irrelevant artistic culture.

-Ward Doubet ${ }^{2}$

\section{Introduction}

By developing an interpretive methodology for contemporary ceramics that promotes the creation of socially relevant meaning, I have challenged established perceptions of criticism in both professional and at educational contexts. Where traditional approaches to ceramics criticism have celebrated the aesthetic and craft qualities of these works, I have argued that ceramic artworks can also be interpreted in a manner in which their social and cultural significance is realized. With this realization comes a clearer recognition of the diverse, multiple, and disjointed realities of ourselves, our culture and our world.

Ibegan the study by conducting a meta-critical investigation of traditional ceramics criticism, which has typically focused its attention on perspectives that relate to the art/craft issue. As a result, I discovered that critical writing on ceramics tends to locate these works at one end or the other of a continuum; as either sculptural or utilitarian. Following the premise that crafts and art actually exist on a continuum, rather than as separate entities, I determined that this debate has ignored ceramic works that have attributes of both art and craft. In response to traditional ceramics criticism in which accusations of "anti-intellectual" writing and the descriptive analysis of the formal qualities of a work abound, I have argued that there are works of art, such as those produced by Adrian Saxe, Edward Eberle, Neil Tetkowski and betty Woodman, among other, that demand to be discussed critically from both art and crafts perspectives. Further, the traditional centers of ceramics, which include issues of style, class, gender ornamentation, decoration, utility, function, and ceramics history have been used as focal points from which critical discus: ion of clay works are usually discussed. By themselves, these criteria limit the critical discourse of ceramics and further remove the works from consideration in many artworld and art educational contexts. Additionally by limiting discussions of ceramic works to only these aesthetic and disciplinespecific concerns without engaging in inquiry of contemporary social, cultural 
and conceptual relevance, discourse is limited to issues and characteristics that directly relate to the physical work.

Without a meta-critical approach, critics neglect connections to aspects of the world that are suggested by and through the symbols in the work. In turn, these connections influence curriculum and allow for an interdisciplinary transfer of knowledge that incorporates diverse components of the world. In response to these conditions, I have argued for a realignment of the traditional philosophical and aesthetic perspectives of ceramics criticism to compliment the explicit and implicit symbolic meaning of codified symbols found in contemporary ceramic works. This realignment of critical perspectives is intended to foster discourse in which the diverse and often contradictory nature of the aesthetic, social and cultural significance of ceramic works is inspired. Conversely, when such discourse is absent, students are restricted from a broad, pluralistic, and divergent understanding of the realities of their society, culture, world and life.

\section{Limits of the Study}

The interpretive methodology developed in this document is limited to a particular domain of contemporary ceramic artworks known as vessels. Vessels by Betty Woodman, Neil Tetkowski, Edward Eberle and Adrian Saxe were specifically chosen for this study because they serve as a fairly random sample of the variety of contemporary styles and techniques and because they embody traits that belong to the traditions of both art and craft objects. For example, works by Adrian Saxe were specitically chosen for this study for two reasons. First, his works appear as both sculptural and narrative creations, depicting antelopes, gears, and buttons as well as including distinctively recognizable elements, such as lids, handles and bases, that can be read literally and symbolically. Second, the student population used for the study did not have an extensive background in the criticism of ceramics or art, and it was my belief that they would be better able, and less intimidated, to engage in critical discourse about the more literal visual elements of Saxe's works such as the spouts, handles and lids, rather than the more abstract and non-objective elements of many other contemporary vessels. Saxe's works provide a middle ground for beginning ceramics critics as they are able to choose whether they wish to address the literal, conceptual. aesthetic or sculptural aspects of the works and the meanings they suggest.

By limiting the study to the critical writing on works by Saxe, Tetkowski, Woodman and Eberle, I excluded works that can be positioned more definitively at either end of the continuum. It is my belief that the methodology ca be applied to ceramic works position at any point on the continuum, from utilitarian jugs, pots and plates displayed at an arts festival to site-specific environmental and performance work. These issues are important and should be addressed by the fields of art criticism, art education and ceramics education, but are beyond the specitic scope of this study. Ultimately, it is the role of the critic, using the methodology as a guide, to make connections between the work of art, regardless of medium, and the larger contexts of society, culture and world. 


\section{The Interpretive Methodology}

The semiotic theories of Umberto Eco and Roland Barthes in combination with the interpretive theory of film critic David Bordwell, functioned as the primary sources for the interpretive methodology. Umberto Eco (1989) contends that when works of art are viewed as open works, they allow us to understand "new aspects of the world." In turn, these open works serve as "epistemological metaphors" for larger aspects of our existence. The interpretive methodology developed in this document directs a similar approach to a select group of contemporary ceramic vessels. Through the methodology, the visual signs that comprise a work, and the works themselves, are viewed as open and therefore can be interpreted to reveal connections to various relevant, and often dissimilar, aspects of the world, past and present.

Roland Barthes' $(1974,1984)$ concept of the function of "good interpretation" in which an artwork must be written "into the text of our lives" also contributes to the theoretical groundwork of the interpretive methodology. My analysis of critical essays written by professional critics and students has determined that some of these authors do make connections between contemporary works of ceramic art and the text of their own lives. These connections are made plausible when the notion of critical level interpretations, put forth by Umberto Eco (1990) is employed. Eco insists that critics must substantiate their interpretations by pointing to a critical level interpretation in which specific examples and explanations of how symbols, whether entire works or portions of them, refer to external content. To better aid students in the construction of socially relevant meaning, Eco's notion of critical level interpretations has been useful. Simply, as the development of the methodology continued, emphasis was placed not he ways in which critics supported their observations through critical level interpretations that delineated exactly how and why particular signs man. As critics provided specific examples from their own lives to support their critical level interpretations, diverse experiences and frames of reference were established.

Film critic David Bordwell (1989) submits that criticism can include everyday language and refuse definite [read traditional] boundaries as to what might constitute relevant data. It is this component of the methodology which best allows critics to write an artwork "into the text of their lives" as Barthes suggests. Bordwell's four types of meaning have also contributed significantly to the development of the methodology. Originally applied to the interpretation of films, his types of meaning have been adapted in this study for use in the interpretation of ceramic works. Bordwell's four types of meaning are significant to the methodology because they provide an effective lens through which professional and student critical essays can be viewed and analyzed.

Fundamentally, the interpretive methodology demands that critics investigate contemporary ceramics for meaning that is based on coded information through inquiry into how the work mean--referentially, explicitly, implicitly, and symptomatically. For clarity, referential meaning reveals the referential nature of the visual elements of a work by demonstrating important 
associations between the work and similar imagery without degenerating into an exercise in formal comparisons. Critics find ways in which they can most directly point to the history and traditions of ceramics, through descriptive statements which address the nature and unique quality of the material of clay, the form of the work, and the techniques and firing process used to construct the work.

In essence, the criteria for referential meaning reflect the limits of typical approaches employed by ceramics critics. I have argued that Bordwell's three other types of meaning provide additional criteria which enhance the critical act and allow for conceptually meaningful and socially relevant interpretations of ceramic works to be constructed. Explicit meaning is essentially obvious to the critic and can be read through the visual signs that denote its meaning. Implicit meaning is slightly hidden and requires the critic to seek the connotations of symbols, codes, or other signs evident in the work. Symptomatic meaning is conceptual in nature, and like implicit meaning, is dependent upon connotations suggested by both the work itself and the signs that comprise the work. Symptomatic meaning is the most conceptual and the furthest removed from the physical aspects of the work. Additionally, symptomatic meaning is pedagogically the most useful type of meaning to construct because it allows a critic to reveal the socially relevant nature of a work by presenting how the work reflects issues, philosophies and consequences that pertain to and exist within contemporary society and culture. In this way, the work of art serves as a point of departure from which cultural and social codes and signs are interpretable. The particular background of the critic and the critical perspective held by the critic also inform the interpretation of ceramic works and ultimately determine the frame of reference from which symptomatic meaning is constructed. As critics from divergent backgrounds compose their symptomatic interpretations of the same work, they will essentially reveal the specifics of their own unique perspectives of the world.

When critics write socially relevant interpretations of ceramic artworks, additional criteria are also employed. For example, effective interpretations span two levels of meaning, semantic and critical. A semantic level reading involves description and comprehension of signs and symbols. A critical level interpretation provides reasoned explanations regarding the reading of a sign or symbol in a particular way. In other words, a critic must supply evidence of research, such as quotations or visual imagery, in order to create plausible connections between evident signs in the work and external texts, contexts, and ideas.

Although, traditionally, ceramics critics have included biographical information in their critical essays, the methodology developed in this study demands that critics include only biographical information relevant to the particular work or works. This content then acts as contextual information which adds to the meaning of the work. Artistic intentions and philosophies proposed by the artist are also considered to e contextual information. Rather than reflecting and supporting artistic intention. however, a good interpretation often challenges and supplies an alternative reading of the work. This is especialiy the case when socially relevant meaning is constructed by critics with different life experiences. 
A critic should also engage in playful conjecture about how and where the visible and conceptual signs provided by the work actually mean by asking questions, raising issues or concerns, and suggesting puns or other visual or conceptual relationship which might be further interpreted. These acts of "textual playfulness" often appear in an interpretation in the form of actual questions or in the form of references to songs, movies, plays and television commercials. As the critic consciously works towards a critical level interpretation of a ceramic work through such acts of conjecture, issues and questions related to previous interpretations about the work often surface, especially when a critic is familiar with the critical writing produced by other critics about a particular ceramic work. When critic are conversant with the work of other critics, they are able to raise questions throughout the construction of an interpretation. Pursuing the answers to such questions becomes a means by which a critical level interpretation is developed.

Additionally, an interpretation can be modified, changed, and altered throughout the critical process. A critic who asks "what could the artist have meant by this?" or "what purpose could this part of the work serve?" establishes questions upon which to build an interpretation based on the answers he or she provides. Understand that as critics construct their own questions, later reconsideration of their point of view is acceptable. For example, a critic who asks "what could the artist have meant by this?" might, during the course of a critical essay, revisit this question, positing several different possible meanings. It is conceivable that over several encounters with a work, its symbols, and contexts, the critic could revise the initial reading and conclude the essay with an interpretation that resolves the uncertainty posited at the beginning of the essay.

The criteria outlined above challenge existing traditional criteria for writing on ceramic artworks. As such, the interpretive methodology established in this study advocates an extension of the critical discourse surrounding ceramic works beyond physical, tactile, material, decorative and utilitarian concerns to include symbolic, conceptual, social, political, cultural and other similar perspectives. These additional considerations, once synthesized with the traditionally established criteria of ceramics criticism, allow critics to interpret ceramic artworks as both aesthetic and conceptually complex objects.

\section{The Methodology Applied}

The methodology was used as a means of understanding selected professional essays written on the ceramic artwork of Edward Eberle, Betty Woodman, Neil Tetkowski, and Adrian Saxe. The results of this investigation suggest that the majority of critical writing on contemporary ceramics attends only to the development of referential and explicit meaning. As such, this writing emphasizes traditional denotations of ceramic works, such as artists' style and methods, visual and tactile qualities of the material, utility, decoration, and status Less frequently, critics of these works produced implicit interpretations in which they addressed the connotations generally linked to these works and the artworld contexts in which they are viewed and appreciated. Few instances of symptomatic [read socially relevant] meaning were observed in most of the professional critical essays analyzed in this study. Critics Peter Schjedahl and 
John Bentley Mays (1985-86, 1987) occasionally produced symptomatic readings of the work of Adrian Saxe. Of the professional critics, Jim Collins (1993), was most successful in that he steadily produced symptomatic meaning for the work of Adrian Saxe. Collin's interpretations most closely reflect the "openness" to which Eco refers, because of the ways in which they inform and reflect how Saxe's works are products of the society and culture in which they exist.

To determine the workability of the methodology, three groups of preservice elementary education teacher, who also had a fairly modest background in the visual arts and ceramics, were asked to construct socially relevant interpretations of the work of Adrian Saxe. Two specific examples of the impact of the methodology on the critical writing of these students in outlined in the following paragraphs.

Once familiar with the criteria of the methodology, student critics frequently constructed socially relevant and symptomatic interpretations, made connections to the diverse nature of the current social landscape, and included references to popular movies, rock music, economics, world history, the art market, industrialization, endangered animals, the environment, spirituality and conceptions of the passage of time. On a critical level, critics are required to supply connections between evident signs in the work and external texts contexts, and ideologies in the world. In the essays by Jennifer, Kevin, and Lisa, the figure of the antelope, based on its position on top of the work and its gesture as a signifier of the animal's vulnerability and the encroachment of humankind on their space.

In another example, Barbara, makes a connection to current cultural examples through the film "The Lion King." Barbara explains that "the father lion tells his son, Simba, that "although they may hunt and kill antelope for their survival, they also maintain respect for this creature and its position in the higher order of all living things." By referencing this particular scene in the Disney movie, Barbara was able to construct a meaningful interpretation of the finial on Saxe's antelope jar. Barbara also included the lyrics of a song by the rock group Phish as critical level support of her interpretation of the antelope, as well as many other animals, "as things are out of human control." She said that she "accidentally came upon some lyrics which appear quite relevant to this theory," which state. "set the gearshift for the high gear of your soul, you've got to run like an antelope out of control." Through these and other examples, students who employed the criteria of the interpretive methodology outlined in this study, demonstrated their ability to interpret contemporary ceramic artworks to reveal plausible aesthetic, social, cultural and political meaning for ceramic works. the findings of this study in turn promote reflective thought about the critical writing and investigation of works of ceramics and the use of these aesthetic and socially meaninglul objects in both ceramics education and art education. 


\section{Conclusion}

In effect, this study offers a redirection in ceramics education in which the development of intellectually critical modes of thought are employed. In other words, I have established a foundation for a pedagogy of ceramics education which engages students in continual acts of critical inquiry with works of art, ideas of fellow students, critical essays, and important issues found in current social and cultural contexts. Such a pedagogy invites the continuos exploration of possibilities and meanings of ceramic works which in turn promotes a more intellectually charged and socially conscious studio setting. Experiences of this type extend beyond narrow and often sterile aesthetic concerns in order to initiate critical discourse that prepares students to enter a critically and intellectually responsible citizenry. This critical discourse is supported by the conscious inclusion of the creation of actual ceramic artworks by students. the studio assignments undertaken by students, in conjunction with socially relevant critical and aesthetic inquiry, would challenge both their critical and visual inquiry through direct investigation of relevant issues in ant, culture, society, and other contexts. As contemporary ceramic artworks, such as those created by Adrian Saxe, continue to simultaneously hold a dialogue with the entire history of ceramics creations and the contemporary contexts in which they exist, the criticism and interpretation of such works, both professionally and in the art classroom, must respond to this complexity.

Ultimately, I have presented an interpretive methodology for contemporary ceramics that analyzes the signifying practice in ceramics criticism. Through the rough and sometimes awkward postmodern discourse we return to the polysemy of traditions and discourses upon which modern-day ceramics has been built. Indeed, there is, and most likely will always be, an element of global unification associated with ceramic objects. In this study, the degree to which the discourse about works of ceramics has advanced this understanding is unclear. What is more obvious to me, though, is that, through the honest philosophical contemplation of works of ceramics, we provide a solid means by which to educate students about, and to gain an understanding of, our relationship with the social and cultural contexts of our world in ways that may be impossible to achieve through any other means.

\section{Footnotes}

TMichael McTwigan (1986). American Ceramics, v. 4, o. 4, p. 7)

Ward Doubet (1989. "The Reemergence of Pluralism," in A merican Ceramics, p. 13 


\section{References}

Barthes, R. (1974). S/Z. Translated by Richard Miller. Hill and Wang; New York. (1984). "From Work to Text," in Art after modernism:

Rethinking representation, Brian Wallis, Ed., The New Museum of Contemporary Art, New York, pp. 169-174.

Bordwell, D. (1989). Making meaning: Inference and rhetoric in the interpretation of cinema, Harvard University Press, Cambridge, Massachusetts.

Collins, J. (1993). "Adrian Saxe and the Postmodern Vessel," in Martha DrexlerLynn's The clay art of Adrian Saxe, Los Angeles County Museum of Art, Los Angeles, California and Thames Hudson Inc., New York, pp. 121-146.

Eco, U. (1989). The open work. Harvard University Press, Cambridge, Massachusetts.

(1990). The limits of interpretation, Indiana University Press, Bloomington, Indiana.

Mays, J.B. (1985-86). "Comment," American Craft, December/January, p. 3839.

(1987). "Stylistic Ensembles," American Craft, v. 47, no. 5 OctoberNovember, p. 42-49. 